\title{
Recycling of foundry sand residuals as aggregates in ceramic formulations for construction materials
}

\author{
N. Quaranta ${ }^{1}$, M. Caligaris ${ }^{1}$, H. López ${ }^{1}$, M. Unsen ${ }^{1}$, J. Pasquini ${ }^{1}$, \\ N. Lalla ${ }^{1} \&$ A. R. Boccaccini ${ }^{2}$ \\ ${ }^{1}$ Universidad Tecnológica Nacional, \\ Facultad Regional San Nicolás, Argentina \\ ${ }^{2}$ Department of Materials, Imperial College London, UK
}

\begin{abstract}
The utilization of residual materials in the fabrication of new products has a strong impact on the preservation of non-renewable natural resources, diminishes energetic consumption and avoids the costs and problems that imply the final disposal of them. The aim of this work is to investigate the recycling of waste foundry sand coming from the process of cast iron for use as aggregate in the manufacture of red clay bricks and tiles. The raw materials, waste foundry sand and clay soil were chemically and microstructural characterized and different samples were designed. Compact bodies were prepared with $10 \%, 20 \%, 30 \%$, $40 \%$ and $50 \%$ (wt $\%$ ) of waste. They were thermally treated in the range $950-$ $1000^{\circ} \mathrm{C}$. The experimental conditions were established taking into account those used for commercial products. The characterization of raw materials and products was carried out using various techniques. The results allow one to conclude that it is feasible to incorporate important quantities of waste foundry sand into the manufacture process of clay bricks and tiles. The best properties were obtained in samples with 30 and $40 \mathrm{wt} \%$ of waste added, taking into account the characteristics required for commercial applications.
\end{abstract}

Keywords: construction material, foundry sand, red clay bricks. 


\section{Introduction}

Waste recycling is very important for environmental conservation and sustainable development. The generation of industrial wastes has increased in recent years in direct relationship to wealth levels and progress of production technology. According to the United States Environmental Protection Agency US EPA [1], approximately 7.6 billion tons of industrial solid waste are generated each year, and disposed in a broad spectrum of U.S. industrial facilities. Several factors, including increase in consumption, obsolescence, increased productivity and low cost of landfills in underdeveloped countries, have contributed to this situation. To deal with this problem, there are two possible and simultaneous ways: reduction in the generation of waste and mitigation of their impact by encouraging waste reuse or recycling.

Industrial wastes such as foundry sand are valuable products that can be widely used in the construction industry [1]. This industry and its auxiliaries can be real receivers of wastes and by-products [2-5].

The aim of this work is to investigate the recycling of waste foundry sand coming from the process of cast iron for use as aggregate in the manufacture of red clay bricks and tiles. The waste material comes from a metallurgical industry placed in the south of Santa Fe Province, Argentina.

This industrial waste, foundry sand, has been characterized by several authors in order to analyze the risk of its disposal in landfills, with particular emphasis on evaluating the content of process additives, and leached compounds [6-11]. Moreover, the feasibility of its reuse in new products has also been analyzed. Guney and collaborators [12] studied the reuse of foundry sand molding as a component of the sub-base material on roads. The obtained results showed that the mixture resistance is highly dependent on the curing period, energy compaction, the presence of cement or lime, and water content. Some authors have studied the replacement of sand in concrete mixtures for waste foundry sand in contents up to $30 \%[13,14]$, getting very good results in relation to critical parameters such as mechanical properties of the obtained materials, which remained within the commercial standards for these products. Additionally, researches on the use of foundry sand in construction of blast furnace channels [15], and in ceramic formulations [16], have led to very encouraging results regarding the use of these waste products in compact sintered bodies.

\section{Experimental}

\subsection{Preparation of compact bodies}

The base materials used for the preparation of the samples were waste foundry sand and red clay soil, commonly used in the construction industry. The waste material was used as collected from the company deposits, and the land used for the mixtures was filtered to remove branches or rocks, but was not selected in particle size. To achieve greater uniformity in the mixture during the tiles 
formation, the soil clods were crushed. The powders obtained, waste foundry sand and clay soil, had particle sizes smaller than $3.35 \mu \mathrm{m}$.

Mixtures containing 10,20,30, 40 and $50 \mathrm{wt} \%$ of residual sand with an addition of $8 \% \mathrm{H}_{2} \mathrm{O}$ were prepared. The samples were pressed $(25 \mathrm{MPa})$ in order to obtain specimens of dimensions $40 \mathrm{~mm} \times 70 \mathrm{~mm} \times 20 \mathrm{~mm}$. Then the samples were dried at room temperature for 4 days before the firing treatment, simulating the conditions of industrial manufacture of these products. For comparative purposes, a sample of clay without waste addition was prepared and treated under the same conditions.

The compacts were subjected to heat treatments which consisted of heating at $5^{\circ} \mathrm{C} /$ minute to $250^{\circ} \mathrm{C}$, remaining at that temperature 1 hour, then heating at $3^{\circ} \mathrm{C} /$ minute to $1000^{\circ} \mathrm{C}$, keeping at this temperature for 2 hours. Finally the samples were cooled to room temperature inside the oven.

To choose the sintering heat treatment, the chemical composition of the materials, the main components in the mixtures $\left(\mathrm{SiO}_{2}, \mathrm{Al}_{2} \mathrm{O}_{3}\right.$ y $\left.\mathrm{Fe}_{2} \mathrm{O}_{3}\right)$, the presence of $\mathrm{Na}$ and $\mathrm{K}$ and the process parameters used by industrial and artisanal brickworks in the area were taken into account.

\subsection{Characterization of raw materials and products}

Several techniques were used to characterize the powders to be used as raw material for the production of the compact bodies and the obtained fired samples: optical microscopy (OM), scanning electron microscopy (SEM), X-ray energy dispersion (EDS), particle size distribution, porosity, compressive and flexural strength and Vickers microhardness measurements, among others.

The obtained sintered bodies were prepared for characterization; pieces of about $1 \mathrm{~cm}^{3}$ were cut, embedded in resin and then polished with different papers and pastes (up to diamond $1 \mu \mathrm{m}$ ) in order to reach a proper surface for microscopic observations and microhardness measurements.

The optical observations were made with Zeiss-Axiotech equipment with a Donpisha 3CCD camera and image digitizer. SEM analyses were carried out through a Phillips 515 scanning electronic microscope with an X-ray detector (EDAX-Phoenix).

The porosity of the samples was determined according to the IRAM 12510 Standard. The mechanical essays were carried out with a Cific Universal Testing Machine, $294 \mathrm{kN}$, and the hardness analyses were made with a Vickers indenter in a HMV-2000 Shimatzu equipment.

The analysis of calcination weight loss on raw materials was carried out at $800^{\circ} \mathrm{C}$ for 3 hours. The calcination process of raw materials has been characterized also through analysis of emissions in relation to the presence of combustion gases and particulate matter emitted, according to local regulations [17]. For this purpose it was used an EPA2001 XILIX air quality equipment with electrochemical sensors technology. The determined gases were nitrogen oxides (NOx), sulphur dioxide $\left(\mathrm{SO}_{2}\right)$, carbon monoxide $(\mathrm{CO})$ and hydrocarbons $(\mathrm{HC})$. The particulate matter was analyzed according to air quality standards as PM10 (particles size less than $10 \mu \mathrm{m}$ ). 


\section{Results and discussion}

\subsection{Characterization of raw materials}

The analysis of scanning electron microscopy and semi-quantitative chemical analysis by EDS on raw materials determined the compositions in the form of single oxides detailed in Table 1.

Table 1: $\quad$ EDS chemical composition of waste and clay soil.

\begin{tabular}{|c|c|c|c|c|c|c|c|c|c|}
\hline & \multicolumn{10}{|c|}{ Oxides [\%] } \\
\cline { 2 - 11 } & $\mathrm{Na}_{2} \mathrm{O}$ & $\mathrm{MgO}$ & $\mathrm{Al}_{2} \mathrm{O}_{3}$ & $\mathrm{SiO}_{2}$ & $\mathrm{~K}_{2} \mathrm{O}$ & $\mathrm{CaO}$ & $\mathrm{TiO}_{2}$ & $\mathrm{FeO}$ & $\mathrm{MnO}$ \\
\hline Sand & 5.2 & 4.4 & 14.7 & 70.1 & 0.3 & 0.7 & --- & 4.4 & 0.2 \\
\hline Clay & 5.0 & 3.7 & 18.0 & 67.1 & 1.6 & 0.9 & 0.5 & 3.2 & --- \\
\hline
\end{tabular}

It can be seen from the table that the composition of the waste, consisting of foundry sand, is chemically similar to the clay used. This is because of these tests are performed on the material as it is extracted from open air deposits of the wastes and on the surface of the particles, where components of the clay deposit and other process aggregates are present, like bentonite material used during molding metallurgical process.

The SEM photographs show the starting materials morphology. In Figure 1 the clay material (soil) utilized is observed. While presenting different initial granulometries, the observation of large particles indicates that they consist of agglomerates of smaller particles, which can be obtained if the agglomerates are properly treated with sieves or mixed with water, occupying less volume. Figure 2 presents the SEM analysis on foundry sand samples. A homogeneous size distribution can be observed, compact particles with rounded sides, without marked angles (Figure 2(a)). It is possible to observe, in small proportion, the presence of different grains, with the appearance of molten phases, which were analyzed by EDS and found to be constituted by $\mathrm{Si}, \mathrm{Ca}$ and $\mathrm{O}$, being ascribed to a calcium silicate phase (Figure 2(b)).
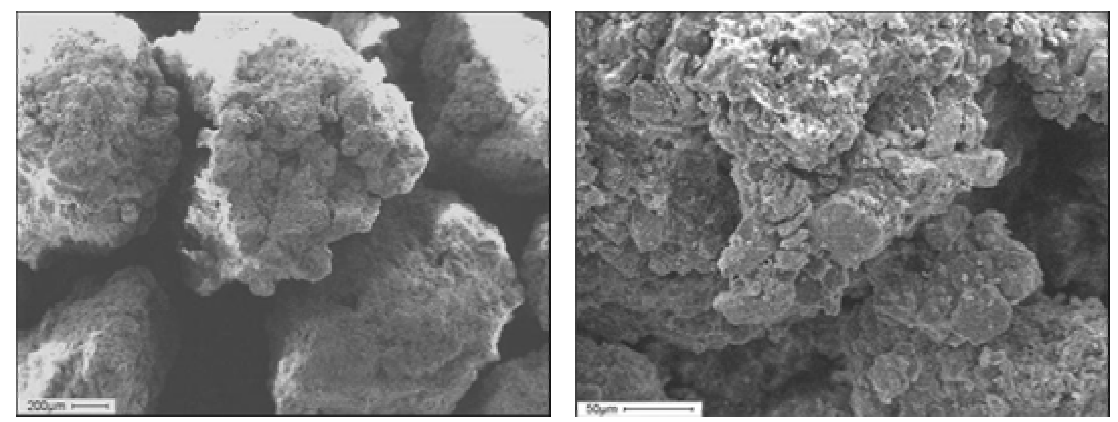

Figure 1: $\quad$ SEM micrographs of the utilized clay. 

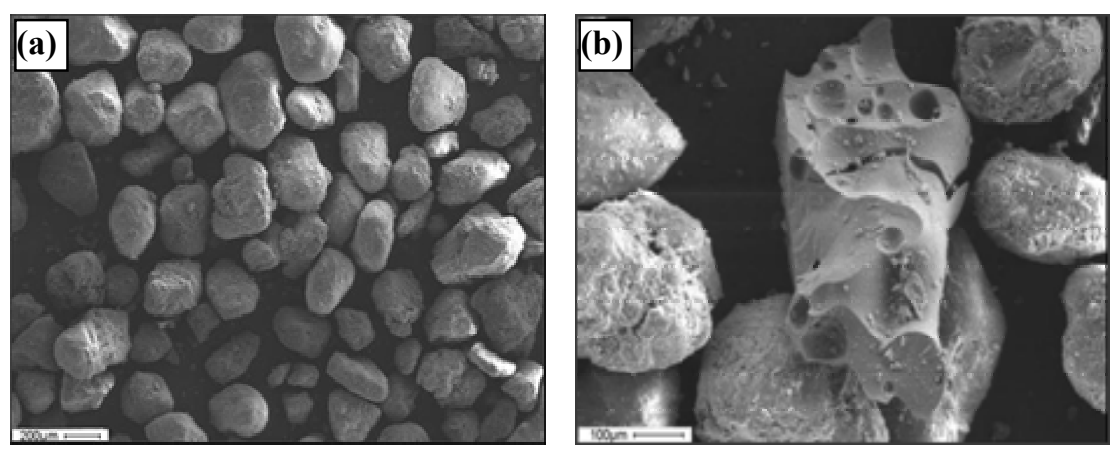

Figure 2: $\quad$ SEM micrographs of the metallurgical waste particles.

\subsection{Characterization of products}

In the macroscopic scale, all products were seen to maintain the planarity of the green compact and retain the edges and vertices. There was no loosing of the structures except the samples with $50 \%$ of waste, which during the cutting process showed a slight loose of material. This suggests a significant degree of sintering in the samples with percentages of waste of 10, 20, 30 and $40 \mathrm{wt} \%$. The permanence of the edges and corners means that the temperatures have not been close to the melting point of the major phases.

The values of the measured permanent expansion, expressed as change in volume percentage, are shown in Figure 3. It is shown that as the proportion of the aggregate increases, the sintered product shrinking decreases up to compositions close to $30 \mathrm{wt} \%$. In samples with $50 \mathrm{wt} \%$ of waste material a dilatation of $2 \%$ was measured. Figure 3 also shows the weight losses during sintering, expressed as percentage. Samples of clay without waste addition reached a value of $\sim 9 \%$.

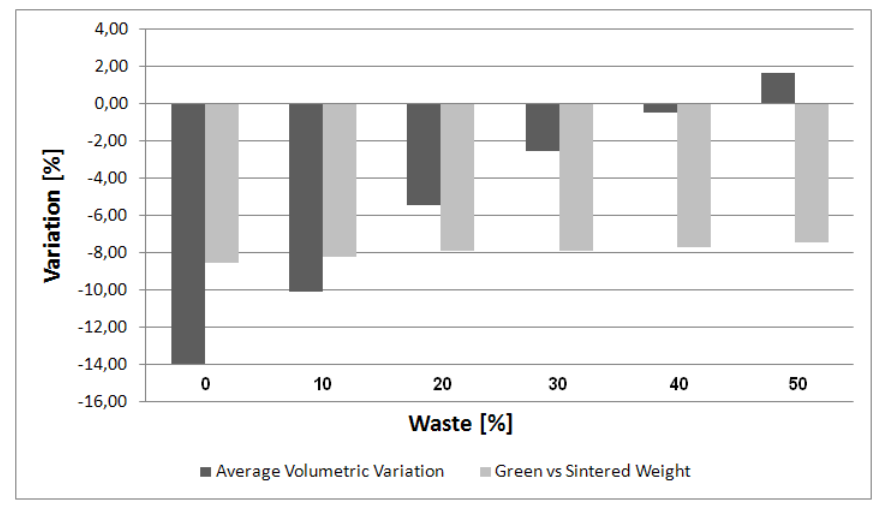

Figure 3: Volumetric variation and weight loss in compact bodies. 


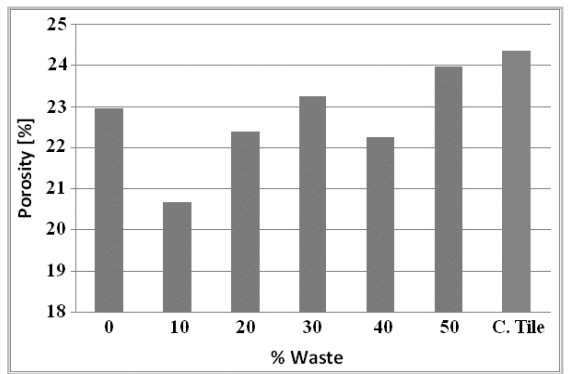

Figure 4: Sintered samples porosity.

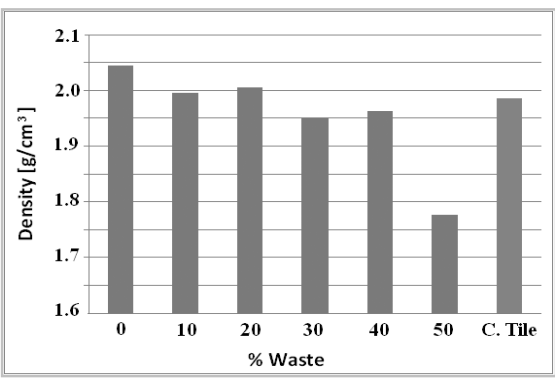

Figure 5: Sintered samples density.

In samples containing foundry sand, weight loss decreases slightly with increasing amount of added waste. This result suggests that in these samples both the clay component and the waste material suffer mass decrease, probably due to organic matter and/or additives present in the starting materials. It is important to mention that the samples were dried at room temperature prior to entering the furnace, so part of the weight loss recorded corresponds to elimination of the initial moisture.

The calcination weight loss of the powder base materials, clay and sand waste, have similar values of $5.73 \%$ and $5.55 \%$ respectively. This explains the slight decrease in weight loss of the bricks as clay is replaced by waste. As mentioned, the emissions in relation to the air quality regulation were characterized. The concentration levels of the combustion gases and particulate matter measured resulted well below the threshold values regulated.

The apparent porosity and density of the sintered samples are presented in Figures 4 and 5, respectively. The final density was calculated as mass per volume on each sintered compact. In order to have a reference point, commercial tiles were tested under the same conditions, and the obtained values have been incorporated into the graph. As it can be seen, the porosity values have a tendency to increase with the increase of foundry sand addition. The higher value of porosity is obtained for the sample with $50 \%$ of the waste, which is consistent with the observed lower degree of sintering of it. In all cases, the porosities of the products were lower than the value determined in the commercial tiles. The density of the compact bodies with wastes addition behaves according with these results, with a tendency to decrease in inverse proportion to the content of the waste in the samples.

The mechanical properties, compressive strength and modulus of rupture, were seen to decrease as the percentage of waste added increased, which is directly related to the results of porosity and degree of sintering macroscopically observed and reported above. The compressive strength values were: 71, 40, 25, 19 and $12 \mathrm{MPa}$ for samples with $10,20,30,40$ and $50 \mathrm{wt} \%$ of waste added, respectively.

The morphological, chemical and microstructural analyses of the samples were made by optical microscopy, scanning electron microscopy and energy dispersive X-ray analysis. The microscopic observation was focused on the 
analysis of the sintering degree of the samples in order to corroborate the observed macroscopic characteristics. In this way the samples containing the highest amount of wastes (30, 40 and $50 \mathrm{wt} \%)$ were considered.

From optical microscopic observations it was possible to determine that the distribution of sand grains in the bricks is different depending on the proportion of waste present. In the samples with $30 \mathrm{wt} \%$ of foundry sand, the sand grains were seen to be uniformly distributed on the inside, while in the surface there were some isolated grains. This is probably due to the pressure during the formation of green bodies which can cause this type of distribution of material. In samples with $40 \mathrm{wt} \%$ waste addition, a homogeneous distribution of sand grains was observed, both in internal and external areas of the brick. Although samples with $50 \mathrm{wt} \%$ sand present homogeneous distribution, both internal and superficial, they have areas of higher concentration of sand grains embedded in the clay matrix.
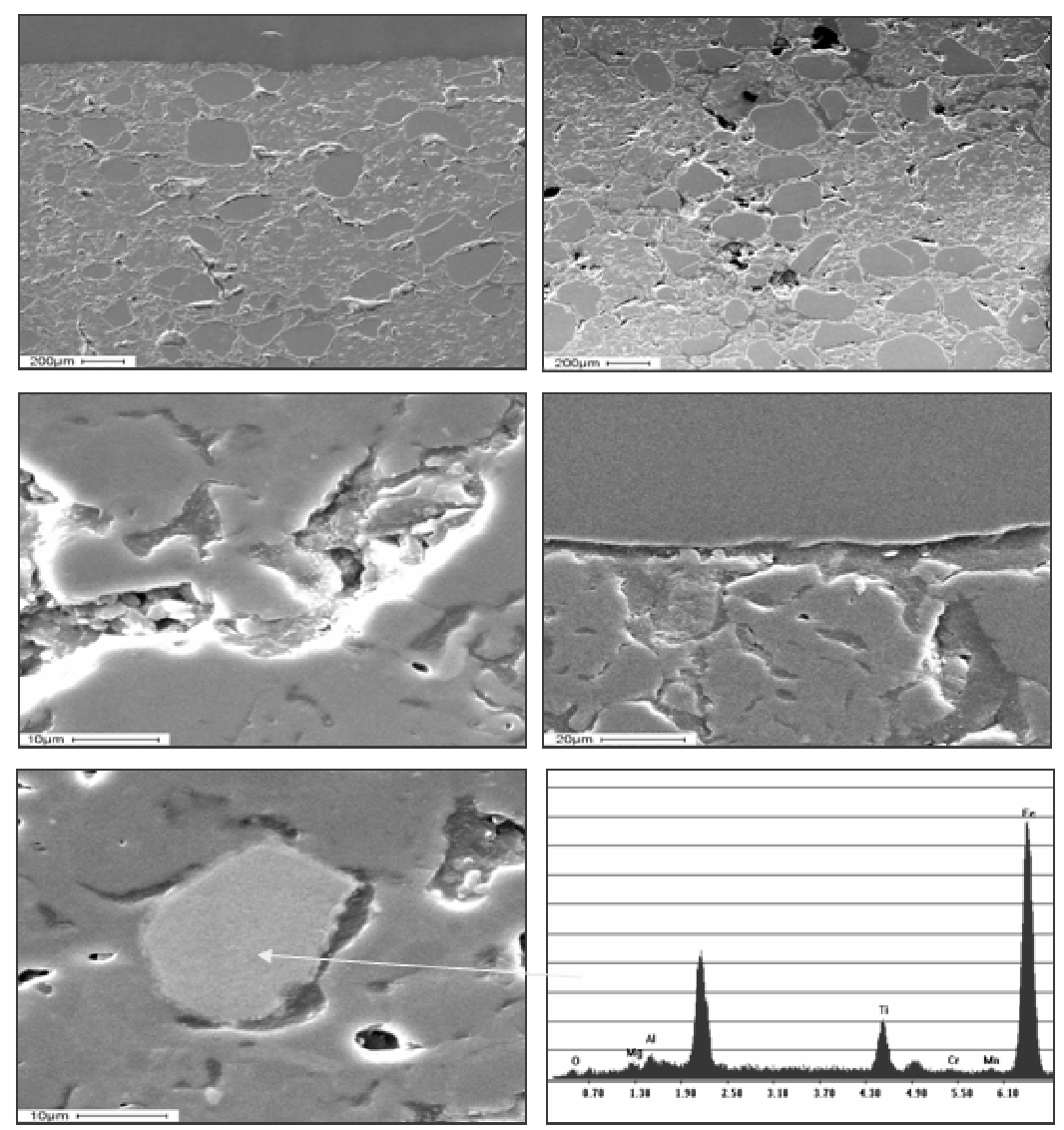

Figure 6: SEM and EDAX analysis of the sample with $40 \mathrm{wt} \%$ foundry sand. 
Similar characteristics have been observed by SEM. Figure 6 shows SEM micrographs of the sample with $40 \mathrm{wt} \%$ of waste. The homogeneous distribution of sand grains in the entire volume of the sample can be observed, both internally and in the area near the surface.

Some sample areas with concentrated internal porosity are observed (top right micrograph), and the presence of a significant degree of sintering is inferred, with binding of particles in the matrix and some vitrified areas, indicating also a good binding interface between matrix and grains. In all samples very small metal particles, essentially Fe and Ti, were detected in the matrix (see Figure 6).

SEM analysis of samples with the highest content of waste added (50 wt $\%)$ shows that the distribution of sand particles was not homogeneous. They concentrate in areas where they are close to each other, leaving high porosity. This fact makes difficult the efficient incorporation of sand particles into the clay brick matrix. This effect can be observed in Figure 7.

Figure 8 shows the SEM and EDS analysis corresponding to an area of sample with $50 \mathrm{wt} \%$ of residual sand, where it is possible to observe the $\mathrm{Ca}$ silicate particles, present in the waste raw material, well incorporated in the brick matrix and keeping their porous structure. This is also noted in the samples with lower content of waste added.
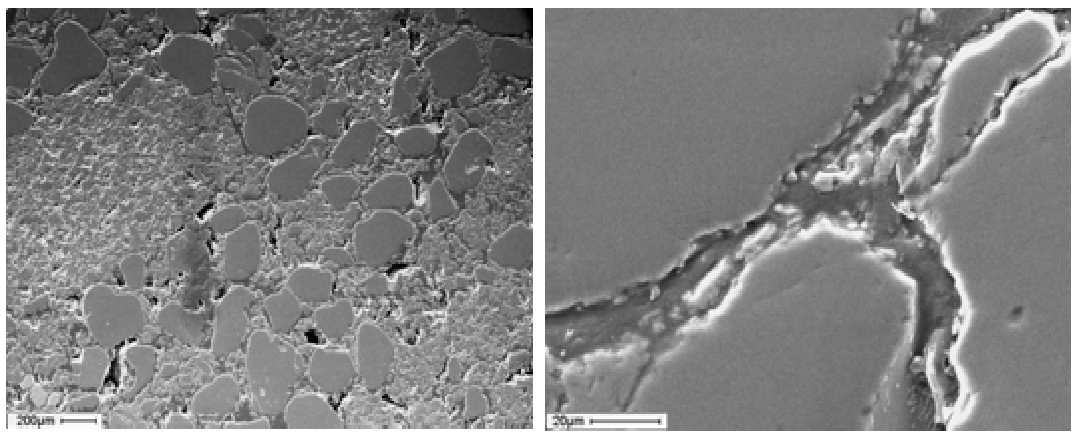

Figure 7: $\quad$ SEM micrographs of a sample with $50 \mathrm{wt} \%$ of residual sand.
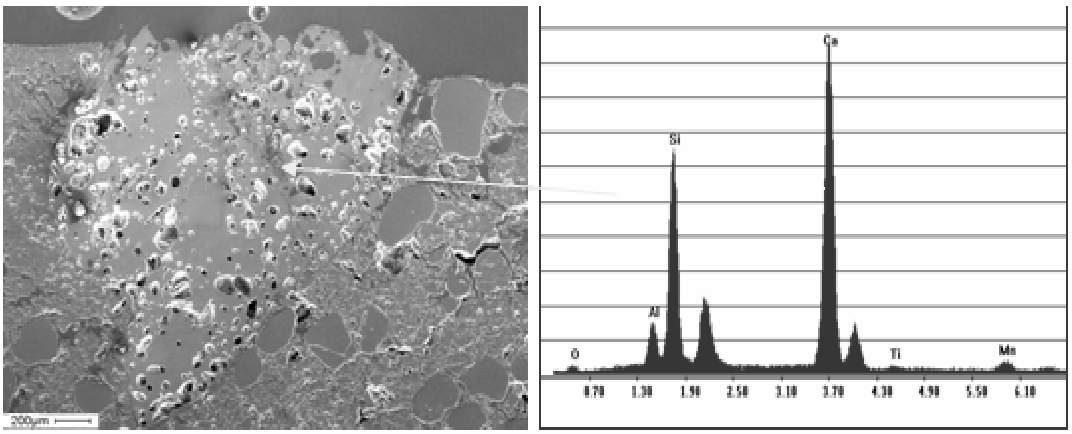

Figure 8: $\quad$ SEM and EDS analysis of a Ca silicate particle in the brick matrix. 
Analyses of Vickers microhardness were conducted covering the whole surface of the samples. While it is not possible to obtain a value for this parameter representing the whole sample, it is feasible to estimate a behavior from the measurement of the microhardness of the different phases present. Microhardness values determined on the sand particles are $\sim 1100 \mathrm{Kg} / \mathrm{mm}^{2}$, with a variation of $\pm 100 \mathrm{Kg} / \mathrm{mm}^{2}$, in all samples tested. However, the determinations made in the clay matrix show lower values: $500 \mathrm{Kg} / \mathrm{mm}^{2}, 200 \mathrm{Kg} / \mathrm{mm}^{2}$ and 80 $\mathrm{Kg} / \mathrm{mm}^{2}$ in samples with 30,40 and $50 \mathrm{wt} \%$ residual sand, respectively. Taking into account the structure of the matrix material, and the determined microhardness values, which diminishes as the residual sand content increases in the mixtures, these values can be related with the different sintering degree attained in the different samples, as discussed above.

The obtained results confirm the high feasibility of using the waste studied in clay based mixtures for the production of compact ceramic bodies. If the objective is the highest incorporation of wastes, it can be concluded that the sample with $40 \mathrm{wt} \%$ sand is the one that achieves greater balance between waste content and final product properties. However, if the objective is the quality of the product, the best ones are obtained with mixtures containing $30 \mathrm{wt} \%$ sand. These products present the lowest volume variation and weight loss (both parameters are related directly to the possibility of formation of microcracks in the material during sintering) and the more dense matrices with a higher degree of sintering. The values of porosity and compressive strength of these samples allow classifying them as dense bricks of type 4, as per the local standard. According to the values of compressive strength, bricks can be classified as type 2 when the value of resistance to compression is between 3.5 and $9.0 \mathrm{MPa}$, type 3 between 9.1 and $15.0 \mathrm{MPa}$, and type 4 with values greater than $15 \mathrm{MPa}$.

\section{Conclusions}

The studies carried out showed the feasibility of incorporating residual foundry sand as coarse aggregate in clay mixtures, to obtain compact ceramic bodies.

In the range of compositions, grain size and other experimental conditions used in this study, the results indicate that the additions of 30 and $40 \mathrm{wt} \%$ of waste are the most appropriate to the intended use of these materials. They provide a balance between incorporating the largest possible amount of wastes, and acceptable characteristics and properties of the products for their use in service as building materials.

In a next step, passage of the laboratory to pilot scale production of bricks with dimensions of construction standards in accordance with the desired product and the current market of brick construction, brick and red tiles is planned.

\section{Acknowledgements}

The authors wish to thank Parana Metal, for the materials used in the present work and Mechanical Department o f FRSN, for mechanical determinations. Financial support by CICPBA and ANPCyT (PICT $\mathrm{N}^{\circ}$ 35672) is gratefully acknowledged. 


\section{References}

[1] US EPA, Industrial Material Recycling, Guide for Industrial Waste Management, www.epa.gov/epaoswer/non-hw/industd/guide/pdf/intro.pdf www.epa.gov/epaoswer/non-hw/industd/guide/index.htm

[2] E. A. Domínguez, R. Uhlmann. Ecological bricks made with clays and steel dust pollutants. Appl. Clay. Sci., 11 (1996) 237-249.

[3] A.A. Francis, R.D. Rawlings, R. Sweeney, A. R. Boccaccini. Processing of coal ash into glass ceramic products by powder technology and sintering. Glass Technol, 43 [2] (2002) 58-62.

[4] K. Skarkynska. Engineering- part 1: properties of mine stone; reuse of coal mining wastes in civil. Waste Management, 15 [1] (1995) 3-42.

[5] K. Skarkynska. Engineering part 2: utilization of mine stone; reuse of coal mining wastes in civil. Waste Management, 15 [2] (1995) 83-126.

[6] R. Dungan, J. Reeves III. Pyrolysis of carbonaceous foundry sand additives: Seacoal and gilsonite. Thermochimica Acta, 460 (2007) 60-66.

[7] Z. Mariachiara, A. Godio. Recovery of foundry sands and iron fractions from an industrial waste landfill. Resources, Conservation and Recycling 48 (2006) 96-411.

[8] K. Bastian, J. Alleman. Microtox characterization of foundry sand residuals. Waste Management 18 (1998) 227-234.

[9] C. Paluszkiewicz, M. Holtzer, A. Bobrowski. FTIR analysis of bentonite in moulding sands. J. Molecular Structure 880 [1-3] (2008) 109-114.

[10] R. Dungan, N. Dees. The characterization of total and leachable metals in foundry molding sands. J. Environ. Management 90 [1] (2009) 539-548.

[11] A. Deng, P. Tikalsky. Geotechnical and leaching properties of flowable fill incorporating waste foundry sand. Waste Management 28 [11] (2008) 2161-2170.

[12] Y. Guney, A. Aydilek, M. Demirkan. Geoenviromental behavior of foundry sand amended mixtures for highway subbases. Waste Management, 26 (2006) 932-945.

[13] Z. Ismail, E. Al-hashmi. Reuse of waste iron as a partial replacement of sand in concrete. Waste Management 28 [11] (2008) 2048-2053.

[14] R. Siddique, G. Schutter, A. Noumowe. Effect of used foundry sand on the mechanical properties of concrete. Construction and Building Materials $\mathbf{2 3}$ [2] (2009) 976-980.

[15] R. Magnani, S. Cava, S. Nascimento, L. Bastos, C. Rossi, E. Leite, C. Paskocimas, J. Varela, E. Longo. Foundry sand recycling in the troughs of Blast furnaces: a technical note. J. Mat. Proc. Tech. 159 (2005) 125-134.

[16] F. Raupp-Pereira, M. Ribeiro, A. Segadaes, J. Labrincha. Extrusion and property characterisation of waste based ceramic formulations. J. Eur. Ceram. Soc. 27 (2007) 2333-2340.

[17] Environmental Polity Secretary Decree 3395/96, Law 5965, modified by Resolution 242/97. Argentina. 